\title{
Prognosis of Pancreatic Cancer Patients with Synchronous or Metachronous Malignancies from Other Organs Is Better than Those with Pancreatic Cancer Only
}

\author{
Su-Jin Shin, MD, PhD' \\ Hosub Park, MD² \\ You-Na Sung, MD2 \\ Changhoon Yoo, MD, $\mathrm{PhD}^{3}$ \\ Dae Wook Hwang, MD, PhD ${ }^{4}$ \\ Jin-hong Park, MD, PhD ${ }^{5}$ \\ Kyu-pyo Kim, MD, PhD ${ }^{3}$ \\ Sang Soo Lee, MD, PhD ${ }^{6}$ \\ Baek-Yeol Ryoo, MD, PhD 3 \\ Dong-Wan Seo, MD, PhD 6 \\ Song Cheol Kim, MD, PhD ${ }^{4}$ \\ Seung-Mo Hong, MD, PhD²
}

${ }^{1}$ Department of Pathology, Hanyang University College of Medicine, Seoul, Departments of ${ }^{2}$ Pathology, ${ }^{3}$ Oncology, ${ }^{4}$ Surgery, ${ }^{5}$ Radiation Oncology, and ${ }^{6}$ Gastroenterology, Asan Medical Center, University of Ulsan College of Medicine, Seoul, Korea

Correspondence: Seung-Mo Hong, MD, PhD Department of Pathology, Asan Medical Center, University of Ulsan College of Medicine, 88 Olympic-ro 43-gil, Songpa-gu,

Seoul 05505, Korea

Tel: $82-2-3010-4558$

Fax: 82-2-472-7898

E-mail: smhong28@gmail.com

Received October 16, 2017

Accepted December 11, 2017

Published Online December 20, 2017

${ }^{*}$ This work was presented in part at the 66th annual fall meeting of the Korean Society of the Pathologists, Seoul, October 2014.

\begin{abstract}
Purpose
Pancreatic cancer associated double primary tumors are rare and their clinicopathologic
\end{abstract} characteristics are not well elucidated.

\section{Materials and Methods}

Clinicopathologic factors of 1,352 primary pancreatic cancers with or without associated double primary tumors were evaluated.

\section{Results}

Of resected primary pancreatic cancers, 113 (8.4\%) had associated double primary tumors, including 26 stomach, 25 colorectal, 18 lung, and 13 thyroid cancers. The median interval between the diagnoses of pancreatic cancer and associated double primary tumors was 0.5 months. Overall survival (OS) of pancreatic cancer patients with associated double primary tumors was longer than those with pancreatic cancer only (median, 23.1 months vs. 17.0 months; $p=0.002$ ). Patients whose pancreatic cancers were resected before the diagnosis of metachronous tumors had a better OS than patients whose pancreatic cancer resected after the diagnosis of metachronous tumors (48.9 months and 13.5 months, $p=0.001$ ) or those whose pancreatic cancers were resected synchronously with non-pancreas tumors (19.1 months, $p=0.043$ ). The OS of pancreatic cancer patients with stomach (33.9 months, $p=0.032$ ) and thyroid ( 117.8 months, $p=0.049$ ) cancers was significantly better than those with pancreas cancer only (17.0 months).

\section{Conclusion}

About $8 \%$ of resected pancreatic cancers had associated double primary tumors, and those from the colorectum, stomach, lung, and thyroid were common. Patients whose pancreatic cancer was resected before the diagnosis of metachronous tumors had better OS than those resected after the diagnosis of metachronous tumors or those resected synchronously. 


\section{Introduction}

Pancreatic ductal adenocarcinoma (hereafter "pancreas cancer") is a fatal malignancy. Only $10 \%$ to $20 \%$ of the patients receive surgical resection at the time of diagnosis, and the mean survival time after surgical resection is up to 10 to 20 months [1]. Recent improvements in surgical techniques and "neoadjuvant" or "down-staging" chemotherapy with or without radiation therapy has led more patients to be candidates for surgical resection and has improved the prognosis of patients not only with pancreatic cancer, but other malignancies as well [2]. Increased application of diagnostic modalities, including computerized tomography (CT), magnetic resonance imaging (MRI), and endoscopic ultrasound guided-fine needle aspiration cytology or biopsy, has led to an increased detection of pancreas cancer as well as other malignancies $[3,4]$.

Up to $10 \%$ of pancreas cancer patients are estimated to be associated with hereditary syndromes [5-7], including hereditary breast and ovarian cancer syndrome, Lynch syndrome, Peutz-Jeghers syndrome, familial atypical multiple mole melanoma syndrome, and hereditary pancreatitis. These syndromes raise the risk of pancreatic cancer with associated malignancies from other organs. Previously reported primary pancreatic cancer with double primary tumors from other organs are rare. Commonly associated synchronous or metachronous malignancies from other organs include cancers of the stomach, colon, thyroid, and genitourinary tract $[8,9]$. However, the clinicopathologic characteristics of pancreatic cancer with double primary tumors have not yet been systematically investigated. Therefore, the purpose of this study was to investigate the clinicopathologic characteristics of pancreatic cancer with double primary tumors and compare them with those of pancreatic cancer only.

\section{Materials and Methods}

\section{Patients}

A total of 1,352 patients underwent curative surgical resection and were pathologically diagnosed with primary pancreatic cancers. Of these 1,352 primary pancreatic cancers, 113 patients $(8.4 \%)$ had pathologically confirmed pancreatic cancer with double primary tumors. Clinical data, including age at the time of diagnosis of pancreatic cancer and associated double primary tumor, sex, family history, stage groupings, time interval of diagnosis between pancreatic cancer and associated double primary tumor, survival outcomes, and therapeutic modalities, were obtained from electronic medical records. Hematoxylin and eosin-stained slides of surgically resected primary pancreatic cancer and histologically confirmed associated double primary tumors including resections and biopsies were carefully reviewed by two pathologists (S.-J.S. and S.-M.H.).

Synchronous double primary tumors from other organs were defined as malignancies occurring at the same time or within an interval of 6 months, while metachronous double primary tumors from other organs referred to malignancies more than 6 months apart from pancreatic cancers and malignant tumors from other organs, as described previously [10]. To estimate the time interval between the diagnoses of primary pancreatic cancer and associated double primary tumor, the diagnosis date of the other malignancies was subtracted from the date of curative surgery of primary pancreatic cancer. TNM staging was used according to the seventh edition of the American Joint Committee on Cancer cancer staging system [11].

\section{Immunohistochemical study}

To exclude metastatic cancers between pancreas and other organs, histopathologic features of the cases were carefully evaluated. For cases with similar histopathologic features as those of pancreatic cancer, including cancers from colorectum, stomach, lung, breast, and thyroid, all available immunohistochemical staining slides were reviewed, and additional immunohistochemical labeling was performed to clarify the diagnosis (Supplemental Methods and S1 Table).

\section{Statistical analysis}

Patient survival rates were estimated using the KaplanMeier method. To estimate the overall survival (OS), patients were followed up from the date of curative surgery of primary pancreatic cancer until the date of death or date of their last visit. The survival curves of two or more different groups were compared with one another by the log rank test and the Cox proportional hazard model. Correlations between patient groups (pancreatic cancer patients with or without associated double primary tumor) and clinicopathologic variables were analyzed using the Student's t test and MannWhitney U test or Pearson's chi-square and Fisher exact tests. Two-sided p-values of $<0.05$ were considered as statistically significant. All statistical analyses were performed using SPSS ver. 18.0 (SPSS Inc., Chicago, IL).

\section{Ethical statement}

After approval from the Institutional Review Board (2015399 ) with waive of the informed consent, pathologic data 
Table 1. Characteristics of pancreatic cancer patients with other primary malignancies

\begin{tabular}{|c|c|}
\hline Characteristic & o. $(\%)(n=113)$ \\
\hline Age, mean (range, yr) & $63.4(38-88)$ \\
\hline \multicolumn{2}{|l|}{ Sex } \\
\hline Male & $82(72.6)$ \\
\hline Female & $31(27.4)$ \\
\hline \multicolumn{2}{|l|}{ No. of other primary malignancies } \\
\hline One & $105(92.9)$ \\
\hline Two & $8(7.1)$ \\
\hline \multicolumn{2}{|l|}{ Family history } \\
\hline None & $65(57.5)$ \\
\hline Other cancer & $43(38.1)$ \\
\hline Pancreatic cancer & $5(4.4)$ \\
\hline \multicolumn{2}{|l|}{ Treatment of pancreatic cancer } \\
\hline Surgery only & $39(34.5)$ \\
\hline Surgery with chemotherapy & $57(50.4)$ \\
\hline Surgery with radiation therapy & $1(0.9)$ \\
\hline $\begin{array}{l}\text { Surgery with chemotherapy and } \\
\text { radiation therapy }\end{array}$ & $16(14.2)$ \\
\hline \multicolumn{2}{|l|}{ Surgical procedures for pancreatic cancer } \\
\hline Distal pancreatectomy & $45(39.8)$ \\
\hline Pylorus-preserving pancreaticoduodenectomy & $34(30.1)$ \\
\hline Whipple operation & $25(22.1)$ \\
\hline Total pancreatectomy & $9(8.0)$ \\
\hline \multicolumn{2}{|l|}{ Tumor location } \\
\hline Head and uncinate & $63(55.8)$ \\
\hline Neck and body & $13(11.5)$ \\
\hline Tail & $37(32.7)$ \\
\hline \multicolumn{2}{|l|}{$\begin{array}{l}\text { Synchronous or metachronous } \\
\text { malignant tumors }\end{array}$} \\
\hline Synchronous malignant tumor & $44(38.9)$ \\
\hline Metachronous malignant tumor & $69(61.1)$ \\
\hline Diagnosis of pancreatic cancer first & $19(16.8)$ \\
\hline Diagnosis of other malignancy first & $50(44.2)$ \\
\hline \multicolumn{2}{|l|}{ Accompanying other malignancies $(n=121)$} \\
\hline Stomach & $26(21.5)$ \\
\hline Adenocarcinoma & $23(19.0)$ \\
\hline Gastrointestinal stromal tumor & $3(2.5)$ \\
\hline Colorectum (adenocarcinoma) & $25(20.7)$ \\
\hline Lung & $18(14.9)$ \\
\hline Squamous cell carcinoma & $8(6.6)$ \\
\hline Adenocarcinoma & $7(5.8)$ \\
\hline Adenosquamous call carcinoma & $1(0.8)$ \\
\hline Large cell carcinoma & $1(0.8)$ \\
\hline Diffuse large B-cell lymphoma & $1(0.8)$ \\
\hline Thyroid (papillary thyroid carcinoma) & $13(10.7)$ \\
\hline Liver (hepatocellular carcinoma) & $9(7.4)$ \\
\hline Breast (invasive ductal carcinoma) & $6(5.0)$ \\
\hline Bladder (urothelial carcinoma) & $4(3.3)$ \\
\hline Prostate (adenocarcinoma) & $3(2.5)$ \\
\hline
\end{tabular}

(Continued)
Table 1. Continued

\begin{tabular}{lc} 
Characteristic & No. (\%) (n=113) \\
Kidney (clear cell renal cell carcinoma) & $3(2.5)$ \\
Appendix & $2(1.7)$ \\
Adenocarcinoma & $1(0.8)$ \\
Low grade appendiceal mucinous neoplasm & $1(0.8)$ \\
Small intestine (gastrointestinal stromal tumor) & $2(1.7)$ \\
Common bile duct (cholangiocarcinoma) & $2(1.7)$ \\
Gallbladder (adenocarcinoma) & $2(1.7)$ \\
Testis (diffuse large B-cell lymphoma) & $1(0.8)$ \\
Uterine cervix (adenocarcinoma) & $1(0.8)$ \\
Esophagus (squamous cell carcinoma) & $1(0.8)$ \\
Larynx (squamous cell carcinoma) & $1(0.8)$ \\
Tonsil (squamous cell carcinoma) & $1(0.8)$ \\
Salivary gland (salivary duct carcinoma) & $1(0.8)$ \\
Interval between other malignancies and & 0.5 \\
pancreatic cancer, median (range, mo) & $(-115$ to 176$)$ \\
\hline
\end{tabular}

from pancreatic cancer patients diagnosed at the Department of Pathology, Asan Medical Center in Seoul, Korea between 1995 and 2014 were reviewed.

\section{Results}

\section{Patient characteristics}

The clinicopathologic characteristics of the patients are summarized in Table 1. A total of 113 patients who had primary pancreatic cancer with associated double primary tumors were retrieved, comprising $8.4 \%$ of the 1,352 primary pancreatic cancers. The mean age of patients with pancreatic cancer with double primary tumors was $63.4 \pm 9.3$ years. The male to female ratio was 2.64. Among these 113 patients, eight had malignancies from more than two organs: four patients had one synchronous and one metachronous tumor, three patients had two synchronous tumors, and one patient had two metachronous tumors (S2 Table). Forty-eight patients had a family history of cancer, mainly gastric, colorectal, lung, and liver cancers. Among these, five patients had a family history of pancreatic cancer.

For treatment of pancreatic cancers, 39 patients received curative surgical resection only, 57 patients received curative surgical resection with chemotherapy before $(n=15)$ or after $(n=42)$ surgery, one patient received curative surgical resection with radiation therapy after surgery, and 16 patients received curative surgical resection with neoadjuvant concurrent chemoradiotherapy $(n=2)$, neoadjuvant chemother- 
apy and adjuvant radiation therapy $(n=4)$, or adjuvant concurrent chemoradiotherapy $(\mathrm{n}=10)$.

Among the 113 patients with primary pancreatic cancer and associated double primary tumors, 45 received distal pancreatectomies, 34 had pylorus-preserving pancreaticoduodenectomies, 25 had Whipple procedures, and nine had total pancreatectomies for primary pancreatic cancers. Ninety-nine patients had curative surgical resections, 10 had chemotherapy, five had transarterial chemoembolization and/or radiofrequency ablation for hepatocellular carcinomas, and seven had conservative treatment for malignancies from other organs.

As seen in Table 1, the most common associated double primary tumors were as follows: 26 stomach (23 adenocarcinomas, three gastrointestinal stromal tumors; $21.5 \%$ ), 25 colorectum (25 adenocarcinomas; 20.7\%), 18 lung (eight squamous cell carcinomas, seven adenocarcinomas, one adenosquamous carcinoma, one large cell carcinoma, one diffuse large B cell lymphoma; 14.9\%), 13 thyroid (papillary thyroid carcinoma; $10.7 \%$ ), and nine liver (hepatocellular carcinoma; $7.4 \%$ ). In addition, six breast (invasive ductal carcinomas; $5.0 \%$ ), four bladder (urothelial carcinomas; 3.3\%), three prostate (adenocarcinomas; 2.5\%), three kidney (clear cell renal cell carcinomas; $2.5 \%$ ), two appendix (one adenocarcinoma, one low grade appendiceal mucinous neoplasm), two small intestine (gastrointestinal stromal tumors), two distal

Table 2. Correlation between pancreatic cancer patients with/ without associated double primary tumors from other organs and clinicopathologic factors

\begin{tabular}{|c|c|c|c|}
\hline Characteristic & $\begin{array}{l}\text { Pancreatic cancer } \\
\text { only }(\mathbf{n}=\mathbf{8 1 8})\end{array}$ & $\begin{array}{l}\text { Pancreatic cancer with } \\
\text { double primary tumors }(n=113)\end{array}$ & p-value \\
\hline Age, mean \pm SD (yr) & $59.3 \pm 9.8$ & $63.4 \pm 9.3$ & $<0.001$ \\
\hline \multicolumn{4}{|l|}{ Sex } \\
\hline Male & $486(59.4)$ & $82(72.6)$ & 0.007 \\
\hline Female & $332(40.6)$ & $31(27.4)$ & \\
\hline \multicolumn{4}{|c|}{ pT category of pancreatic cancer } \\
\hline pT1 & $12(1.5)$ & $2(1.8)$ & 0.234 \\
\hline pT2 & $23(2.8)$ & $4(3.5)$ & \\
\hline pT3 & $756(92.4)$ & $99(87.6)$ & \\
\hline pT4 & $27(3.3)$ & $8(7.1)$ & \\
\hline \multicolumn{4}{|c|}{ pN category of pancreatic cancer } \\
\hline pN0 & $343(42.9)$ & $49(45.4)$ & 0.623 \\
\hline $\mathrm{pN1}$ & $457(57.1)$ & $59(54.6)$ & \\
\hline \multicolumn{4}{|c|}{ M category of pancreatic cancer } \\
\hline pM0 & $782(95.6)$ & $109(96.5)$ & 0.672 \\
\hline pM1 & $36(4.4)$ & $4(3.5)$ & \\
\hline \multicolumn{4}{|l|}{ Lymphovascular invasion } \\
\hline Absent & $480(59.6)$ & $66(58.9)$ & 0.900 \\
\hline Present & $326(40.4)$ & $46(41.1)$ & \\
\hline \multicolumn{4}{|l|}{ Perineural invasion } \\
\hline Absent & $117(16.2)$ & $24(22.9)$ & 0.089 \\
\hline Present & $606(83.8)$ & $81(77.1)$ & \\
\hline \multicolumn{4}{|l|}{ Differentiation } \\
\hline Well & $81(10.2)$ & $10(10.0)$ & 0.323 \\
\hline Moderate & $601(75.4)$ & $81(81.0)$ & \\
\hline Poor & $115(14.4)$ & $9(9.0)$ & \\
\hline \multicolumn{4}{|l|}{ Treatment } \\
\hline Surgery & $308(37.7)$ & $39(34.5)$ & 0.862 \\
\hline Surgery with CTx & $402(49.1)$ & $57(50.4)$ & \\
\hline Surgery with RTx & $4(0.5)$ & $1(0.9)$ & \\
\hline Surgery with CTx+RTx & $104(12.7)$ & $16(14.2)$ & \\
\hline
\end{tabular}

Values are presented as number (\%) unless otherwise indicated. SD, standard deviation; CTx, chemotherapy; RTx, radiation therapy. 
A
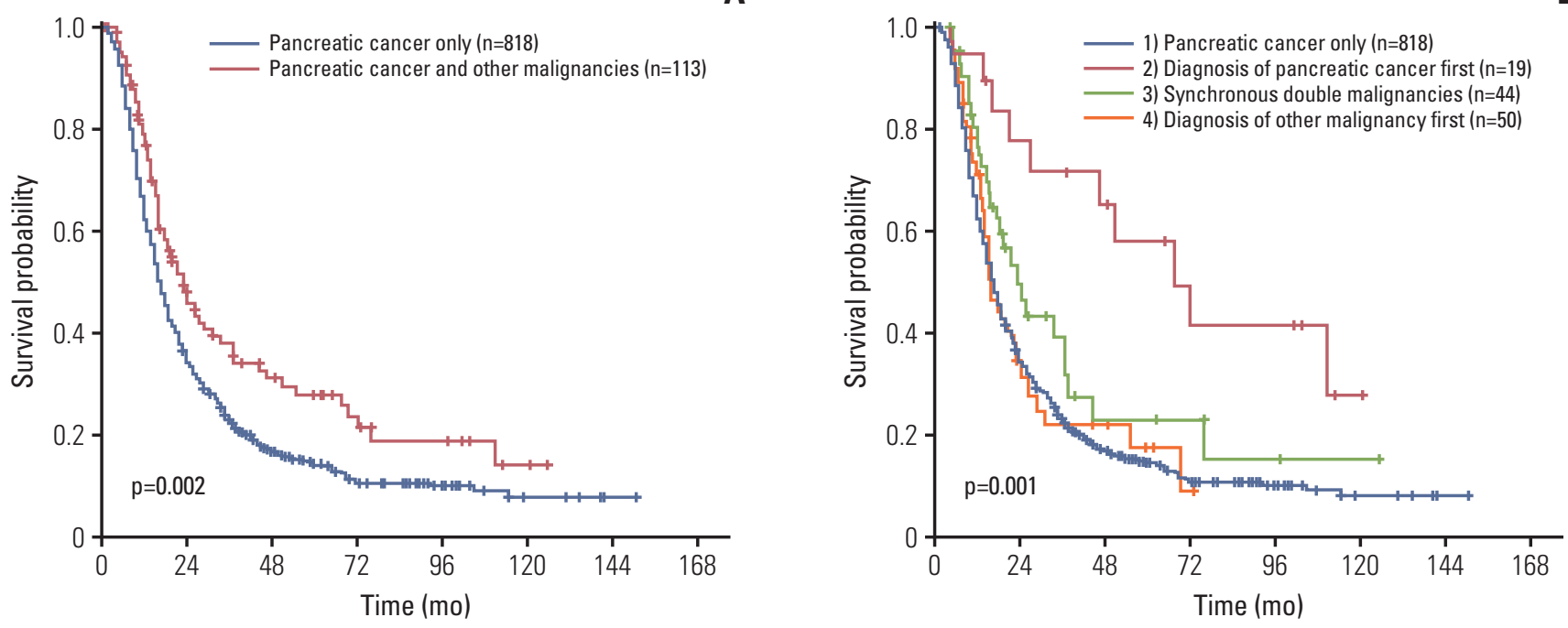

Fig. 1. Overall survival (OS) comparison between pancreatic cancer with or without accompanying malignancies from other organs. (A) The OS for pancreatic cancer patients with synchronous or metachronous malignant tumors from other organs was significantly longer than patients with pancreatic cancer only (median, 23.1 months vs. 17.0 months; estimated 5-year survival rate, $27.7 \%$ vs. $14.4 \%$; $\mathrm{p}=0.002$ ). (B) Patients who were diagnosed with pancreatic cancer earlier than other malignancies had better OS (median, 48.9 months) than those with pancreatic cancer only (median, 17.0 months), pancreatic cancers with synchronous other malignant tumors (median, 19.1 months) or pancreatic cancer after other malignancies (median, 13.5 months; OS comparison, $\mathrm{p}=0.001 ; 1$ vs. 2 , $\mathrm{p}=0.001 ; 2$ vs. $3, \mathrm{p}=0.043 ; 2$ vs. $4, \mathrm{p}=0.001 ; 1$ vs. $3, \mathrm{p}=0.077 ; 1$ vs. 4 , $\mathrm{p}=0.859 ; 3$ vs. 4 , $\mathrm{p}=0.149$ ).

bile duct, two gallbladder (adenocarcinomas), one testis (diffuse large B-cell lymphoma), one uterine cervix (adenocarcinomas), one esophagus (squamous cell carcinoma), one larynx (squamous cell carcinoma), one tonsil (squamous cell carcinoma), and one salivary gland (salivary duct carcinoma) were also observed.

The pathologic $\mathrm{T}$ categories of pancreatic cancer were variable with predominant pT3 (99 cases, 87.6\%) (Table 2). Pathologic $\mathrm{T}$ categories of associated double primary tumors were also variable with common pT1 (41 cases, 33.9\%), pT2 (28, $23.1 \%)$, and pT3 $(26,21.5 \%$ ) categories (S3 Table).

The intervals between the diagnosis of primary pancreatic cancer and associated double primary tumors were 0.5 months (range, -115 to 176 months). Of 113 pancreatic cancers with double primary tumors, 44 patients $(38.9 \%)$ had synchronous double primary tumors and $69(61.1 \%)$ had metachronous double primary tumors. Among four patients who had malignancies from two organs (one synchronous and one metachronous tumor), of the two tumors, the tumor with worse behavior was used as a reference. Among 69 patients with metachronous double primary tumors, 19 patients were diagnosed with pancreatic cancer before the associated double primary tumor, while 50 patients were diagnosed with pancreatic cancers after the associated double primary tumors. The median follow-up period after sur- gical resection of the pancreatic cancer was 16.8 months (range, 0.9 to 143.2 months). During the follow-up period, 71 patients $(62.8 \%)$ died. Among 113 patients who had double primary tumors, 49 patients had diabetes and two patients had liver cirrhosis. However, none of them died from these diseases. The estimated 5-year OS rate in patients with pancreatic cancer with double primary tumors was $27.7 \%$.

\section{Comparison of pancreatic cancer with double primary tumors}

Clinicopathologic features from 818 patients with primary pancreatic cancer only between 2000 and 2009 were compared to those of patients with pancreatic cancer with double primary tumors. The associations between pancreatic cancer with or without associated double primary tumors and clinicopathologic factors are summarized in Table 2. Patients with pancreatic cancer with double primary tumors were significantly older than those with pancreatic cancer only (63.4 \pm 9.3 and 59.3 \pm 9.8 years old, respectively; $p<0.001)$. Pancreatic cancer with double primary tumors were more predominant in males than those with pancreatic cancer only (72.6\% and $59.4 \%$, respectively, $\mathrm{p}=0.007)$. However, there were no associations between pancreatic cancer with double primary tumors and other clinicopathologic factors. 
A
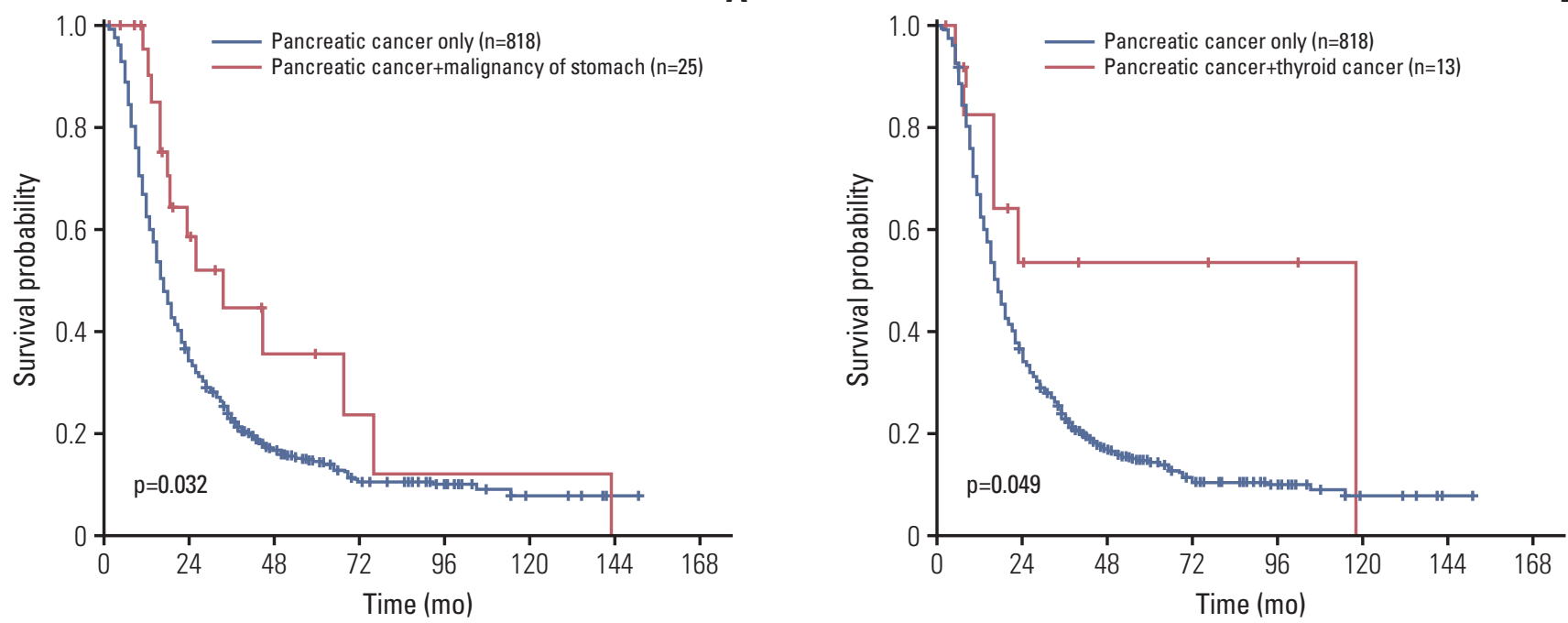

C
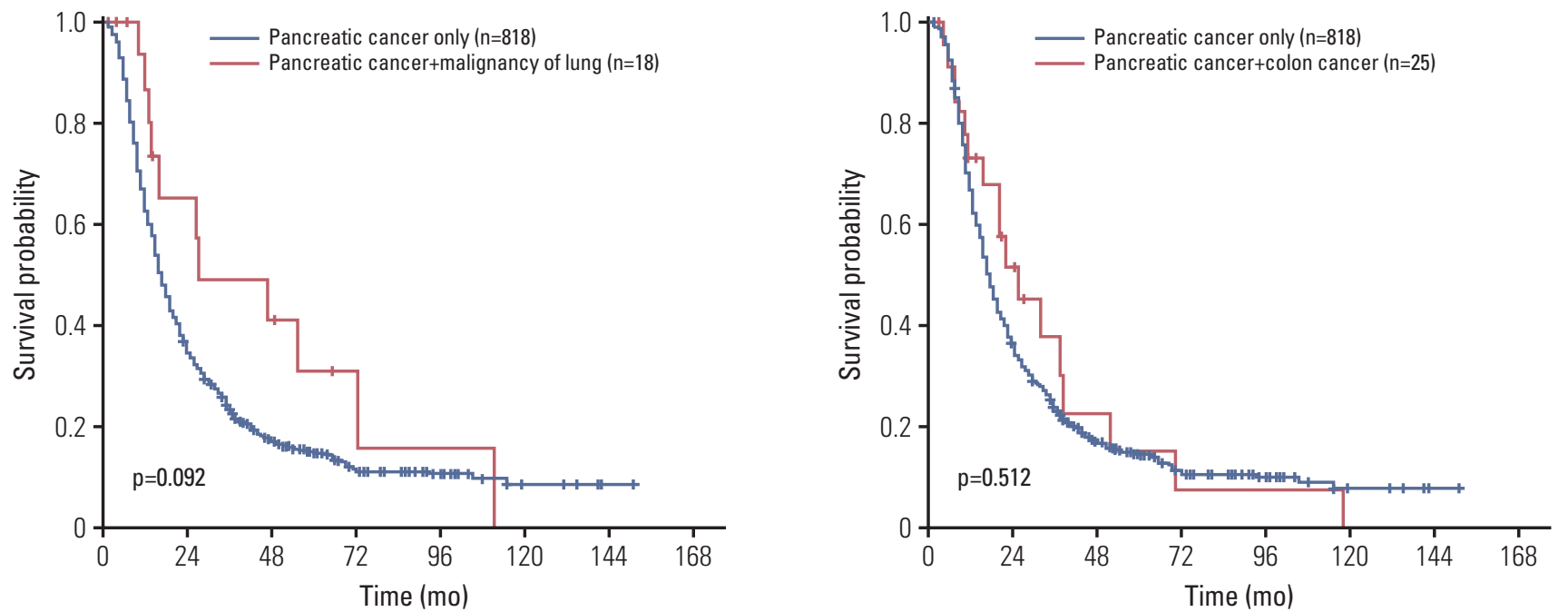

Fig. 2. Overall survival (OS) comparison between pancreatic cancer patients with or without accompanying stomach (A), thyroid (B), lung (C), and colon (D) cancers. (A) Pancreatic cancer plus stomach cancer patients had significantly better OS than those with pancreatic cancer only (median, 33.9 months vs. 17.0 months; $\mathrm{p}=0.032$ ). (B) Pancreatic cancer plus thyroid cancer patients had significantly better OS than those with pancreatic cancer only (median, 117.8 months vs. 17.0 months; $\mathrm{p}=0.049$ ). (C) Pancreatic cancer plus lung cancer patients had a tendency for a longer survival than those with pancreatic cancer only (median, 27.4 months vs. 17.0 months; $\mathrm{p}=0.092$ ). (D) No significant survival difference was observed between pancreatic cancer plus colon cancer patients and those with pancreatic cancer only (median, 24.9 months vs. 17.0 months; $\mathrm{p}=0.512$ ).

\section{Survival analysis}

The OS for pancreatic cancer with double primary tumors was significantly longer than patients with pancreatic cancer only (median, 23.1 months vs. 17.0 months; estimated 5-year 
Table 3. Correlation between clinicopathologic factors and pancreatic cancer patient subgroups (diagnosis of pancreatic cancer first vs. other 3 groups)

\begin{tabular}{|c|c|c|c|}
\hline Characteristic & $\begin{array}{l}\text { Diagnosis of pancreatic } \\
\text { cancer first }(n=19)\end{array}$ & $\begin{array}{l}\text { Pancreatic cancer, merged } \\
\text { other } 3 \text { groups }(n=912)\end{array}$ & p-value \\
\hline Age, mean \pm SD (yr) & $59.2 \pm 9.2$ & $59.8 \pm 9.8$ & 0.702 \\
\hline \multicolumn{4}{|l|}{ Sex } \\
\hline Male & $16(84.2)$ & $552(60.5)$ & 0.054 \\
\hline Female & $3(15.8)$ & $360(39.5)$ & \\
\hline \multicolumn{4}{|c|}{ pT category of pancreatic cancer } \\
\hline pT1 & $1(5.3)$ & $13(1.4)$ & 0.401 \\
\hline pT2 & $1(5.3)$ & $26(2.9)$ & \\
\hline pT3 & $17(89.5)$ & 838 (91.9) & \\
\hline pT4 & 0 & $35(3.8)$ & \\
\hline \multicolumn{4}{|c|}{$\mathrm{pN}$ category of pancreatic cancer } \\
\hline $\mathrm{pN} 0$ & $9(52.9)$ & $383(43.0)$ & 0.464 \\
\hline $\mathrm{pN1}$ & $8(47.1)$ & $508(57.0)$ & \\
\hline \multicolumn{4}{|c|}{ M category of pancreatic cancer } \\
\hline $\mathrm{pM} 0$ & $19(100)$ & $872(95.6)$ & 1.000 \\
\hline pM1 & 0 & $40(4.4)$ & \\
\hline \multicolumn{4}{|l|}{ Lymphovascular invasion } \\
\hline Absent & $10(55.6)$ & $536(59.6)$ & 0.810 \\
\hline Present & $8(44.4)$ & $364(40.4)$ & \\
\hline \multicolumn{4}{|l|}{ Perineural invasion } \\
\hline Absent & $9(60.0)$ & $132(16.2)$ & $<0.001$ \\
\hline Present & $6(40.0)$ & $681(83.8)$ & \\
\hline \multicolumn{4}{|l|}{ Differentiation } \\
\hline Well & $3(18.8)$ & $88(10.0)$ & 0.516 \\
\hline Moderate & $11(68.8)$ & $671(76.2)$ & \\
\hline Poor & $2(12.5)$ & $122(13.8)$ & \\
\hline \multicolumn{4}{|l|}{ Treatment } \\
\hline Surgery & $6(31.6)$ & $341(37.4)$ & 0.931 \\
\hline Surgery with CTx & $10(52.6)$ & $449(49.2)$ & \\
\hline Surgery with RTx & 0 & $5(0.5)$ & \\
\hline Surgery with $\mathrm{CT} x+\mathrm{RT} x$ & $3(15.8)$ & $117(12.8)$ & \\
\hline
\end{tabular}

Values are presented as number (\%) unless otherwise indicated. SD, standard deviation; CTx, chemotherapy; RTx, radiation therapy.

creatic cancer before, at the same time as, or after the diagnosis of malignant tumors from other organs. Survival times were then compared among the groups. Pancreatic cancer patients who were diagnosed with pancreatic cancer prior to malignancies from other organs had better OS (median, 48.9 months) than those who were diagnosed with pancreatic cancer after malignancies from other organs (median, 13.5 months; $p=0.001$ ), those with synchronously diagnosed pancreatic cancer and malignancies from other organs (median, 19.1 months; $\mathrm{p}=0.043$ ), and those with pancreatic cancer only (median, 17.0 months; $\mathrm{p}=0.001$ ). However, no significant survival differences were observed between patients with synchronously diagnosed pancreatic cancer and malignancies from other organs and those who were diagnosed after malignancies from other organs $(\mathrm{p}=0.149)$, or those diagnosed with pancreatic cancer only $(p=0.077)$. Similarly, no significant survival differences were observed between pancreatic cancer patients diagnosed after malignancies from other organs and those with pancreatic cancer only $(\mathrm{p}=0.859)$ (Fig. 1B, S4 Table).

In the subgroup analyses, the OS of pancreatic cancer patients with common associated double primary tumor were compared with those of patients with pancreatic cancer only. The OS of patients with pancreas plus stomach cancer (median, 33.9 months) and patients with pancreas plus thyroid cancer (median, 117.8 months) had significantly better 
Table 4. Univariate and multivariate analyses for overall survival in pancreatic cancer patients with or without double primary tumors from other organs

\begin{tabular}{|c|c|c|c|c|c|c|}
\hline \multirow{2}{*}{ Characteristic } & \multicolumn{3}{|c|}{ Univariate analysis } & \multicolumn{3}{|c|}{ Multivariate analysis } \\
\hline & HR & $95 \% \mathrm{CI}$ & p-value & HR & $95 \% \mathrm{CI}$ & p-value \\
\hline $\begin{array}{l}\text { Pancreatic cancer with double primary tumors } \\
\text { vs. pancreatic cancer only }\end{array}$ & 1.463 & $1.142-1.874$ & 0.002 & 1.358 & $1.033-1.785$ & 0.029 \\
\hline Differentiation & & & $<0.001$ & & & $<0.001$ \\
\hline Well & 1 & & & 1 & & \\
\hline Moderate & 1.271 & $0.989-1.632$ & 0.061 & 1.158 & $0.879-1.524$ & 0.297 \\
\hline Poor & 2.239 & $1.658-3.022$ & $<0.001$ & 2.052 & $1.476-2.852$ & $<0.001$ \\
\hline pT category & & & $<0.001$ & & & 0.023 \\
\hline pT1-2 & 1 & & & 1 & & \\
\hline pT3 & 1.975 & $1.325-2.944$ & 0.001 & 1.665 & $0.989-2.803$ & 0.055 \\
\hline pT4 & 3.707 & 2.184-6.292 & $<0.001$ & 2.474 & $1.287-4.753$ & 0.007 \\
\hline pN category (pN0 vs. pN1) & 1.651 & $1.424-1.915$ & $<0.001$ & 1.438 & $1.216-1.700$ & $<0.001$ \\
\hline M category (M0 vs. M1) & 1.522 & $1.084-2.138$ & 0.015 & 1.489 & $0.013-2.188$ & 0.043 \\
\hline Lymphovascular invasion & 1.594 & $1.380-1.841$ & $<0.001$ & 1.426 & $1.212-1.677$ & $<0.001$ \\
\hline Perineural invasion & 1.838 & 1.471-2.297 & $<0.001$ & 1.478 & $1.162-1.880$ & 0.001 \\
\hline $\begin{array}{l}\text { Treatment } \\
\text { (surgery vs. surgery with CTx and/or RTx) }\end{array}$ & 1.023 & 0.872-1.199 & 0.783 & & & \\
\hline Chemotherapy (adjuvant vs. neoadjuvant) & 1.084 & 0.899-1.309 & 0.398 & & & \\
\hline
\end{tabular}

HR, hazard ratio; CI, confidence interval; CTx, chemotherapy; RTx, radiation therapy.

OS than those with pancreas cancer only (median, 17.0 months; $\mathrm{p}=0.032$ and $\mathrm{p}=0.049$, respectively). Patients with pancreatic cancer plus lung cancers had a tendency for a longer survival than those with pancreatic cancer only (median, 27.4 months vs. 17.0 months; $\mathrm{p}=0.092$ ). However, no significant survival differences were observed between patients with both pancreas plus colon cancers and those with pancreatic cancer only (median, 24.9 months vs. 17.0 months; $\mathrm{p}=0.512$ ) (Fig. 2A-D).

4. Comparison of clinicopathologic features of patients whose pancreatic cancer diagnosed first and those with other groups

To identify factors associated with better outcome in pancreatic cancer patients who were diagnosed with pancreatic cancer prior to malignancies from other organs than other three group patients, clinicopathologic factors were compared between pancreatic cancer patients who were diagnosed with pancreatic cancer prior to malignancies from other organs and merged other three group patients (including patients whose pancreatic cancer diagnosed after malignancies from other organs, patients whose pancreatic cancer diagnosed synchronously with malignancies from other organs, and patients diagnosed pancreatic cancer only). Perineural invasion was more frequently present in merged other three group-patients than patients who were diagnosed with pancreatic cancer prior to malignancies from other organs. However, there was no other association between pancreatic cancer patients who were diagnosed with pancreatic cancer prior to malignancies from other organs and merged other three group-patients (Table 3).

\section{Patient survival according to other clinicopathologic fac- tors}

The following clinicopathologic factors were associated with worse survival of pancreatic cancer patients (Table 4): poor histologic differentiation $(\mathrm{p}<0.001)$, higher $\mathrm{pT}(\mathrm{p}<$ $0.001), \mathrm{pN}(\mathrm{p}<0.001)$, and $\mathrm{M}(\mathrm{p}=0.015)$ categories, and presence of lymphovascular $(\mathrm{p}<0.001)$ and perineural $(\mathrm{p}<0.001)$ invasions by univariate analysis. However, no significant survival differences were noted based on therapies.

\section{Multivariate analysis}

Multivariate analyses were performed to assess which factors remained independent predictors of OS after adjusting for factors that were significant by univariate analyses. As noted in Table 4, pancreatic cancer with associated double primary tumors $(\mathrm{p}=0.029)$, well differentiation $(\mathrm{p}<0.001)$, lower $\mathrm{pT}(\mathrm{p}=0.023)$, $\mathrm{pN} 0(\mathrm{p}<0.001)$, and $\mathrm{M} 0(\mathrm{p}=0.043)$ cate- 
Table 5. Incidence of pancreatic cancer with associated synchronous or metachronous cancers from other organs according to previous studies

\begin{tabular}{lccc} 
Reference & Year & Incidence (\%) & No. of cases \\
\hline Tagawa et al. [12] & 2017 & 1.17 & $7 / 599$ \\
Ghothim et al. [13] & 2015 & 0.75 & $3 / 400$ \\
Muller et al. [14] & 2012 & 1.36 & $16 / 1,178$ \\
Gerdes et al. [9] & 2000 & 18.8 & $13 / 69$ \\
Kamisawa et al. [15] & 1993 & 16.6 & $45 / 270$ \\
Makino et al. [16] & 1984 & 5.6 & $134 / 2,394$ \\
\hline Yoshimori et al. [17] & 1982 & 10.8 & $12 / 111$ \\
\hline Maruchi et al. [18] & 1979 & 20.0 & $23 / 113$ \\
\hline Cubilla et al. [19] & 1978 & 17.0 & $65 / 380$ \\
\hline Kasumi et al. [20] & 1977 & 7.3 & $9 / 123$ \\
\hline Moertel et al. [21] & 1961 & 3.1 & $29 / 921$ \\
\hline Warren and Gates [22] & 1932 & 1.2 & $15 / 1,259$ \\
\hline
\end{tabular}

gories, and a lack of lymphovascular $(\mathrm{p}<0.001)$ and perineural $(\mathrm{p}=0.001)$ invasions remained the most potent predictors of better OS (Table 4).

\section{Subgroup analysis of pT3 category pancreatic cancers}

Because the predominant pancreatic cancers were $\mathrm{T} 3$ category, an additional subgroup analysis was performed for pancreatic cancers with T3 category $(\mathrm{n}=855)$. T3 category patients with pancreatic cancer with double primary tumors had significantly better OS ( $\mathrm{p}=0.014)$ than those with pancreatic cancer only. Histologic differentiation $(\mathrm{p}<0.001), \mathrm{pN}$ $(\mathrm{p}<0.001)$ and $\mathrm{M}(\mathrm{p}<0.001)$ categories, as well as lymphovascular $(p<0.001)$ and perineural $(p=0.001)$ invasions were also independent predictors for better OS in T3 category pancreatic cancer patients with associated double primary tumors (S5 Table).

\section{Discussion}

Pancreatic cancer with double primary tumors are rare, and their reported incidence has varied from $0.75 \%$ to $20.0 \%$ among previous publications (Table 5) [9,12-22]. Among these published studies, the largest cohort was in a Japanese autopsy study in which the authors evaluated 2,394 autopsy cases and found 134 cases of pancreatic cancer with double primary malignancies from other organs, reporting an incidence of 5.6\% [16]. Except for this autopsy study, the present study has the largest cohort to date, and we also found the largest number of double primary cancers, including pancre- atic cancer. Incidence of pancreatic cancer with double primary tumors was $8.4 \%$ in the present study, which was similar to those found in previous studies with smaller study cohorts $[16,17,20]$. In addition, the most common locations of associated double primary tumors in the present study were found in the stomach $(21.5 \%)$, colorectum $(20.7 \%)$, lung $(14.9 \%)$, and thyroid (10.7\%). Conversely, the most common locations of associated double primary tumors in previous reports include stomach $(\mathrm{n}=51)$, thyroid $(\mathrm{n}=35)$, lung $(\mathrm{n}=22)$, and colorectum $(\mathrm{n}=20)$ (S6 Table) $[8,12,14-17,20]$.

Only a few published studies have analyzed the survival of patients with pancreatic cancer with double primary tumors. Particularly, survival analyses in subgroups according to diagnosis time have not been previously conducted. Gerdes and colleagues reported 13 double primary cancers among 69 pancreatic cancer cases (18.8\%), and they observed no differences in clinical parameters including OS differences between patients with pancreatic cancer only and pancreatic cancer patients with additional primary tumors [9]. Previously, Muller et al. [14] evaluated 16 synchronous or metachronous renal cell carcinomas and pancreatic cancers and they observed no survival difference between 1,178 pancreatic cancer only patients and 16 pancreatic cancer with renal cell carcinoma (median survival time, 15.9 months vs. 12.6 months). In the present study, we observed only three pancreatic cancer cases with synchronous or metachronous renal cell carcinomas, and no OS difference was observed between pancreatic cancer patients with renal cell carcinoma and those with pancreatic cancer only. However, the number of cases included in the previous and present studies was too small to draw a solid conclusion regarding the survival of pancreatic cancer patients with renal cell carcinoma. We observed that pancreatic cancer patients with stomach and 
thyroid cancers had a longer survival than those with pancreatic cancer only. In addition, pancreatic cancer patients with lung cancer had a tendency for longer survival than those with pancreatic cancer only. The survival time of patients with pancreatic cancer with double primary tumors was different based on the origin of associated double primary tumor.

In the subgroup analysis of double primary cancers, pancreatic cancer patients who were diagnosed with pancreatic cancer prior to malignancies from other organs had better OS than the other three groups, which included pancreatic cancer patients diagnosed with pancreatic cancer after malignancies from other organs, pancreatic cancer patients synchronously diagnosed with malignancies from other organs, and patients with pancreatic cancer only. The results of the present study were relatively similar with those of previous studies. For example, Tagawa et al. [12] reported seven nonsmall cell lung cancers in patients with a history of pancreatic cancers, and the estimated 5-year survival rate was 68.6\%, which was better than the survival rate of patients with pancreatic cancer only. Additionally, Muller et al. [14] reported 16 primary pancreatic cancers among patients with renal cell carcinomas. All 16 cases had renal cell carcinomas that were diagnosed first or synchronously with pancreatic cancers, and the estimated 5-year survival rate was 23.1\% [14]. Similarly, Eriguchi et al. [8] reported 12 synchronous or metachronous double primary cancers of the pancreas and other organs, and all of the patients in their study either had pancreatic cancer diagnosed after malignancies from other organs or synchronously diagnosed pancreatic cancer and malignancies from other organs; the estimated 5-year survival rate was only $11.1 \%$ (S7 Table).

We observed that patients with pancreatic cancer with double primary tumors had better OS than those with pancreatic cancer only. Particularly, patients who were diagnosed with pancreatic cancer earlier than metachronous double primary tumors had better survival. However, pancreatic cancer patients diagnosed after metachronous double primary tumors or with synchronous double primary tumors had similar survival times as those diagnosed with pancreatic cancer only. To remove any bias caused by varying $T$ categories, a subgroup analysis was performed with the inclusion of T3 category pancreatic cancers only, and the results were the same as that which included all $\mathrm{T}$ categories.

A plausible explanation for this finding is that regular follow-ups with CT and/ or MRI imaging for surgically resected pancreatic cancer patients may detect second primary malignancies from other organs in their early disease stages. Also, in the present study, we observed that the mean age of patients with pancreatic cancer with double primary tumors was significantly older than that of patients with pancreatic cancer only (63.4 years vs. 59.3 years). This finding could be explained by pancreatic cancer patients who have longer survivals may have more of a chance develop or discover second primary cancers. In addition, because perineural invasion was more frequently observed in merged other three group-patients (including patients whose pancreatic cancer diagnosed after malignancies from other organs, patients whose pancreatic cancer diagnosed synchronously with malignancies from other organs, and patients diagnosed pancreatic cancer only) than pancreatic cancer patients who were diagnosed with pancreatic cancer prior to malignancies from other organs, it also could be explained by pancreatic cancer patients who were diagnosed with pancreatic cancer prior to malignancies from other organs may have less chance of perineural invasion by unknown mechanisms, such as active immunologic eradication of perineural infiltrating cancer cells, which may lead longer survivals of pancreatic cancer patients who were diagnosed with pancreatic cancer prior to malignancies from other organs than merged other 3 grouppatients.

Up to $10 \%$ of pancreatic cancer cases are associated with hereditary syndromes, such as Lynch syndrome [5]. Lynch syndrome is a dominantly inherited cancer syndrome characterized by an increased risk of numerous cancers from the intestinal tract and other organs, including colorectum, endometrium, stomach, small intestine, ovary, renal pelvis, ureter, biliary tract, and pancreas [23,24]. In our cohort, 56 patients may have had Lynch syndrome-associated cancers, such as 25 colorectal $(20.7 \%)$ and 23 gastric $(19.0 \%)$ adenocarcinomas, four urothelial carcinomas $(3.3 \%)$ and four cholangiocarcinomas (3.3\%). Forty-eight patients $(42.5 \%)$ had a family history of pancreatic cancers (five cases, $4.4 \%$ ) and other cancers (43 cases, 38.1\%). Because pancreatic cancer patients with Lynch syndrome have a better survival [25], some patients included in the present study may have had Lynch syndrome.

Because our institution is the tertiary hospital for pancreatic cancer patients, follow-up information of some patients was missing. Therefore, we observed OS rather than cancer specific survival. This could be one limitation of the present study.

In summary, about $8 \%$ of surgically resected pancreatic cancers in our cohort had associated double primary tumors. Carcinomas from colorectum, stomach, lung, and thyroid were common with pancreatic cancers. Pancreatic cancer patients with stomach and thyroid cancers had better OS than those with pancreatic cancer only. Patients whose pancreatic cancers were resected before the diagnosis of metachronous double primary tumors had better OS than patients whose pancreatic cancers were resected after the diagnosis of metachronous double primary tumors or those with resected pancreatic cancers and synchronous double primary tumors synchronously. 


\section{Electronic Supplementary Material}

Supplementary materials are available at Cancer Research and Treatment website (http://www.e-crt.org).

\section{Conflicts of Interest}

Conflict of interest relevant to this article was not reported.

\section{Acknowledgments}

This research was funded by a grant (2016-554) from the Asan Institute for Life Sciences, Seoul, Korea.

\section{References}

1. Bosman FT, Carneiro F, Hruban RH, Theise ND. WHO classification of tumors of the digestive system. 4 th ed. Lyon: IARC Press; 2010.

2. Donahue TR, Reber HA. Surgical management of pancreatic cancer: pancreaticoduodenectomy. Semin Oncol. 2015;42: 98-109.

3. Bali MA, Metens T, Denolin V, Delhaye M, Demetter P, Closset $\mathrm{J}$, et al. Tumoral and nontumoral pancreas: correlation between quantitative dynamic contrast-enhanced MR imaging and histopathologic parameters. Radiology. 2011;261:456-66.

4. Balachandran A, Bhosale PR, Charnsangavej C, Tamm EP. Imaging of pancreatic neoplasms. Surg Oncol Clin N Am. 2014;23:751-88.

5. Bartsch DK, Gress TM, Langer P. Familial pancreatic cancer: current knowledge. Nat Rev Gastroenterol Hepatol. 2012;9: 445-53.

6. Takai E, Yachida S, Shimizu K, Furuse J, Kubo E, Ohmoto A, et al. Germline mutations in Japanese familial pancreatic cancer patients. Oncotarget. 2016;7:74227-35.

7. Cho JH, Bang S, Park SW, Chung JB, Song SY. BRCA2 mutations as a universal risk factor for pancreatic cancer has a limited role in Korean ethnic group. Pancreas. 2008;36:337-40.

8. Eriguchi N, Aoyagi S, Hara M, Okuda K, Tamae T, Fukuda S, et al. Synchronous or metachronous double cancers of the pancreas and other organs: report on 12 cases. Surg Today. 2000;30:718-21.

9. Gerdes B, Ziegler A, Ramaswamy A, Wild A, Langer P, Bartsch DK. Multiple primaries in pancreatic cancer patients: indicator of a genetic predisposition? Int J Epidemiol. 2000;29: 999-1003.

10. Moertel CG. Multiple primary malignant neoplasms: historical perspectives. Cancer. 1977;40(4 Suppl):1786-92.

11. Edge SB, Byrd DR, Compton CC, Fritz AG, Greene FL, Trotti AE. AJCC cancer staging handbook. 7th ed. New York: Springer; 2010.

12. Tagawa T, Ito K, Fukuzawa K, Okamoto T, Fujinaga A, Kawasaki $\mathrm{T}$, et al. Surgical outcomes of non-small cell lung cancer in patients with a history of pancreaticobiliary cancer. Anticancer Res. 2017;37:3307-9.

13. Ghothim M, Havlik R, Skalicky P, Klos D, Vrba R, Straznicka $\mathrm{J}$, et al. Synchronous cancer duplicities of pancreas and stom- ach / kidney and their surgical treatment. Rozhl Chir. 2015;94: 251-5.

14. Muller SA, Pahernik S, Hinz U, Martin DJ, Wente MN, Hackert $\mathrm{T}$, et al. Renal tumors and second primary pancreatic tumors: a relationship with clinical impact? Patient Saf Surg. 2012;6:18.

15. Kamisawa T, Isawa T, Egawa N, Tsuruta K, Okamoto A, Kawamura T, et al. Study on pancreatic cancer associated with other primary malignancies. Suizo. 1993;8:164-9.

16. Makino TK, Takahashi S, Maruyama H, Kohara T, Yokose $Y$, Emi Y, et al. Clinicopathology of pancreatic cancer analyzed from annual of the pathological autopsy cases in Japan. Tan To Sui. 1984;5:761-8.

17. Yoshimori M, Tajiri H, Nakamura K, Kishi K, Ozaki H. Clinical significance of multiple cancers including pancreatic cancer: report on 12 cases. Gan No Rinsho. 1982;28:165-7.

18. Maruchi N, Brian D, Ludwig J, Elveback LR, Kurland LT. Cancer of the pancreas in Olmsted County, Minnesota, 1935-1974. Mayo Clin Proc. 1979;54:245-9.

19. Cubilla A, Fitzgerald PJ. Pancreas cancer. I. Duct adenocarcinoma. A clinical-pathologic study of 380 patients. Pathol Annu. 1978;13 Pt 1:241-89.

20. Kasumi F, Togo S, Ota T, Takagi K, Kato H. Study of cases with double carcinoma of the stomach and pancreas. Gan No Rinsho. 1977;23:1306-14.

21. Moertel CG, Dockerty MB, Baggenstoss AH. Multiple primary malignant neoplasm. I. Introduction and presentation of data. Cancer. 1961;14:221-30.

22. Warren S, Gates O. Multiple primary malignant tumors: a survey of the literature and a statistical study. Am J Cancer. 1932;16:1358-414.

23. Jasperson KW, Tuohy TM, Neklason DW, Burt RW. Hereditary and familial colon cancer. Gastroenterology. 2010;138: 2044-58.

24. Jun SY, Lee EJ, Kim MJ, Chun SM, Bae YK, Hong SU, et al. Lynch syndrome-related small intestinal adenocarcinomas. Oncotarget. 2017;8:21483-500.

25. Malesci A, Laghi L, Bianchi P, Delconte G, Randolph A, Torri $\mathrm{V}$, et al. Reduced likelihood of metastases in patients with microsatellite-unstable colorectal cancer. Clin Cancer Res. 2007;13:3831-9. 